\title{
ESTRATÉGIAS DE REPRODUÇÃO DAS ELITES POLÍTICAS E INTELECTUAIS NO BRASIL EM FINS DO XIX
}

\section{POLTICAL AND INTELLECTUAL ELITES REPRODUCTION STRATE- GIES IN BRAZLL BY THE END OF $19^{\text {HH }}$ CENTURY}

\author{
Rodrigo da Rosa Bordignon*
}

\section{Introdução}

0 ambiente social, político e cultural brasileiro da segunda metade século XIX se apresenta como um momento propício à apreensão das estratégias de reprodução, as quais permitem aos diferentes indivíduos e grupos conservar ou transformar seus patrimônios e, assim, manter ou melhorar suas posições na estrutura social. A análise de tal fenômeno torna-se ainda mais interessante na medida em que se constata que os diagnósticos estabelecidos nas ciências sociais enxergam, no último quartil do século XIX, as condições favoráveis para a ascensão daqueles até então excluídos do sistema de privilégios (econômicos, culturais e políticos), representado pela monarquia. Nas décadas finais do Segundo Reina- do, então, teríamos uma ruptura intraelite, resultado da "percepção da necessidade de reformas essenciais na organização da economia e do sistema político". A transformação do sistema simbólico de referências caminharia, assim, a pari passu com a redefınição das fronteiras sociais produzidas pelo baralhamento dos "recursos materiais, políticos e simbólicos de todos os grupos" que foram "afetados tanto pela crise política quanto por uma modernização conservadora" (ALONSO, 2001, p. 42).

Em termos mais gerais, o deslocamento de setores sociais para os centros administrativos provinciais e, assim, a ampliação das atividades urbanas, a concentração fundiária sob a nova roupagem do café, e a desclassificação social de parte dos grupos ligados à posse de terras e títulos, têm

\footnotetext{
* Professor do Departamento de Sociologia e Ciência Política e do Programa de Pós-Graduação em Sociologia Política - UFSC - (Florianópolis/SC/Brasil). E-mail: rrbordignon@hotmail.com
} 
impacto na estrutura do campo do poder, tencionando as bases sociais de acesso às posições dominantes e, assim, incidindo sobre a divisão do trabalho de dominação. Efetivamente, há uma transformação no estado dos instrumentos de reprodução, primeiramente pela transição do eixo econômico, a modernização da economia açucareira e a ascensão e diversificação produtiva ligada ao complexo cafeeiro, e, em seguida, pela "situação inflacionária no mercado de diplomas escolares" e a consequente "desvalorização do título universitário”, especialmente da década final do séc. XIX (MICELI, 1979, p. 38). Como seria de se esperar, a mudança dos recursos necessários ao acesso às posições socialmente mais rentáveis é acompanhada pela reorientação dos princípios de legitimação. Ocorre, pois, uma transformação das justificativas acionadas pelos agentes para dar sentido às suas ações e explicar os meios de ingresso nas posições conquistadas, conservadas ou pretendidas, dissimulando, assim, a violência que fundamenta a desigualdade de chances.

A combinação específica entre a emergência de uma nova "simbologia da excelência” (BOURDIEU, BOLTANSKI e SAINT MARTIN, 1973, p. 80), e as transformações da morfologia social produz, de fato, a representação de uma democratização da sociedade, defendida pelos grupos vencedores no pós-proclamação da república. Neste contexto, o novo regime passa a ser definido como o produto e o lugar de ascensão das "classes populares" (BORDIGNON, 2016, p. 244). 0 problema mais geral é que o discurso da democratização tende, por um lado, a esquecer a recomposição das relações de força entre as diferentes classes, frações de classe e grupos sociais em uma perspectiva relacional e, por outro, a enfatizar os quadros de mobilidade social, perdendo de vista os princípios de seleção social e os mecanismos institucionais que reproduzem a restrição das escolhas. Isso conduz, portanto, às sombras a diversidade de formas de hierarquização que se reproduzem em múltiplos níveis, tanto do espaço social em geral, como dos espaços de ação específicos nos quais os agentes se inserem.

Como alternativa ao enfrentamento do problema das relações entre origens e destino social, sem perder de vista o caráter processual do mundo social e os efeitos performativos da transição entre princípios de legitimação, o presente artigo busca apreender as estratégias de reprodução de determinadas frações de elite em fins do século XIX. Enquanto um conjunto de fenômenos através dos quais "indivíduos ou famílias tendem, consciente ou inconscientemente, a conservar ou aumentar seu patrimônio e, correlativamente, a manter ou melhorar sua posição" (BOURDIEU, 2007, p. 122), as estratégias de reprodução só se realizam ao preço de uma reconversão dos recursos possuídos em recursos de outra espécie. Isso corre pelo caráter relacional e dinâmico das relações entre determinadas condições de existência e o estado do sistema dos instrumentos de reprodução disponíveis, expressas na conexão entre as disposições e as prospecções. Note-se que essas relações envolvem tanto as modalidades diferencias de apropriação dos recursos herdados ou adquiridos, quanto a percepção e apreciação dos caminhos possíveis em situações de transformação das oportunidades sociais. Reconverter significa, então, deslocar-se em um espaço em movimento, colocando em evidencia a lógica processual e enfatizando um princípio metodológico fundamental para 
a dessubstancialização do mundo social: todos os elementos se definem por suas relações com os demais.

A proposta, portanto, é focalizar o sistema de estratégias de reprodução que expressa os fluxos de deslocamento verticais ou horizontais -, caracterizados pela relação entre origens sociais, formação escolar e destino de elites políticas e intelectuais de fins do XIX. Em termos gerais, os padrões desenhados conectam-se aos perfis específicos que caracterizam as chances inscritas em diferentes condições sociais de existência, permitindo entrever a ligação entre as regularidades do conjunto e seus efeitos sobre os trajetos dos agentes em pauta. 0 plano de exposição se divide em três partes. A primeira, esforça-se por situar os procedimentos metodológicos, classificatórios, e os limites da análise proposta. A segunda está centrada no exame das relações entre origens e destinos, buscando identificar o sistema de estratégias de reprodução e confrontá-lo, na medida do possível, com as transformações morfológicas do período. Por fim, busca-se conectar as relações estatísticas gerais aos perfis específicos de estratégias que caracterizam determinados padrões, procurando ilustrar a multiplicidade de recursos que respaldam as condições sociais de possibilidade de acesso aos cargos, e de reprodução das posições na estrutura social.
1. Informações disponíveis, formas de classificação e limites da análise

O conjunto das informações utilizadas neste artigo é proveniente de uma pesquisa mais geral centrada no problema das relações entre as transformações nos instrumentos de reprodução, nos princípios de legitimação e seus efeitos para a recomposição social de frações de elites em fins do XIX. Com base nisso, foram reunidas informações biográfıcas o mais exaustivamente possível sobre políticos e intelectuais. Na ocasião, a centralidade atribuída às duas frações esteve associada aos esforços em apreender em que medida os modos de seleção e recrutamento e os trajetos eram impactados pelo diagnóstico de uma progressiva divisão do trabalho de dominação (MICELI, 1976, 1979) ou se, ao contrário, tratava-se de segmentos que operavam através dos mesmos princípios de hierarquização e modos de apropriação das posições e cargos mais rentáveis. Em linhas gerais, buscava-se compreender qual o alcance e a diversidade das transformações sociais em suas relações com o campo do poder, no período em questão. Isso implicou, evidentemente, a mobilização de múltiplas fontes de informação, o confronto constante entre a base de dados elaborada (Tabela 1) e as condições sociais, culturais e institucionais de emergência e ainda a transformação do campo do poder enquanto espaço relacional analiticamente construído.

Tabela 1: População em análise

\begin{tabular}{lll}
\hline & $\mathrm{N}$ & $\%$ \\
Elites políticas & 266 & 56,8 \\
Elites intelectuais & 202 & 43,2 \\
Total & 468 & 100 \\
\hline
\end{tabular}

Fonte: elaborada pelo autor. 
A população foi definida a partir de uma coorte sincrônica situada em 18961898, considerada como o ponto de chegada de uma geração que se viu às voltas com a transição entre o regime monárquico e o republicano. 0 caráter de profundidade histórica foi operacionalizado a partir do confronto entre as diferentes gerações que compõem a base de dados, e os recursos de que dispunham para alçar as posições em análise. Em grande medida, isso permitiu visualizar a dinamicidade das relações entre origens - local de nascimento e atividade do pai -, e destinos - primeira ocupação descrita -, notadamente ao confrontá-las com um contexto de modificação dos princípios de legitimação que respaldam o acesso aos cargos e posições disponíveis. É justamente nesse esforço de operacionalização conjunta das condições sociais e das estratégias de reprodução, que o caráter de profundidade associado à análise prosopográfica ganha sentido, notadamente, ao fornecer os meios para apreender tanto os deslocamentos de conjunto quanto os desvios e bifurcações que compõem os trajetos individuais.

As frações de elite consideradas conectaram-se, portanto, a duas dimensões especificas da vida social, e são definidas ou por sua condição especifica - escritores -, ou pelos cargos ocupados no período - professores de ensino superior e ocupantes de cargos públicos eletivos ou por nomeação. No que se refere aos escritores, a população analisada foi constituída por um critério que visava a prevenção contra a consagração posterior decorrente, em grande medida, do efeito de descoberta associado ao resgate de autores e obras e sua posterior eternização no cânone literário e, consequentemente, na história da literatura (CHARLE, 2018). A alternativa foi recorrer ao reconhecimento atribuído pelos contemporâneos, operacio- nalizado a partir do mapeamento dos "círculos literários" e do exame de trabalhos de consagração publicados no período, em especial a História da Literatura Brasileira, de Silvio Romero (1888), e a História da Literatura Brasileira, de José Veríssimo (1915). Operando deste modo, é possível perceber quem os contemporâneos consideravam como adversários e, ao contrário, os que estavam fora do jogo.

No caso das elites políticas, foram retidos todos que ocupavam cargos em nível federal (presidente e vice-presidente, ministros, senadores e deputados federais) e os cargos majoritários estaduais (governador e vice-governador) em 1896 - a primeira legislatura após a "República da Espada”. Para os professores de ensino superior, a lista foi elaborada a partir da seleção das faculdades: a Faculdade de Medicina do Rio de Janeiro; a Faculdade Livre de Ciências Jurídicas e Sociais do Rio de Janeiro; a Faculdade Livre de Direito do Rio de Janeiro; a Faculdade de Direito de São Paulo; Faculdade de Medicina e Farmácia de Porto Alegre. Neste caso, os objetivos estiveram associados à comparação entre as faculdades fundadas no início do regime monárquico, e aquelas que surgem com a instauração da República, apreendendo, assim, as transformações no espaço dos possíveis decorrentes da expansão dos cargos em pauta.

Em termos gerais, os principais limites da análise proposta advêm tanto das condições de classificação das variáveis de origem e de destino, quanto das fontes disponíveis ao detalhamento dos perfis. Se por um lado, o esforço em apreender os fluxos entre origens e destinos permite colocar em relação as condições sociais que presidem os deslocamentos tendenciais, enfatizando uma abordagem 
"balística" que visa traçar as trajetórias (CONINCK e GODARD, 1990), por outro, o adensamento descritivo dos perfis é fundamental. Isso porque a redução do quadro descritivo geral, em nome das convenções de equivalência destinadas à codificação das variáveis e ao tratamento estatístico, é apenas uma das etapas da pesquisa, faltando restituir, em seguida, a multiplicidade de informações que compõem os perfis dos agentes em pauta. Como alternativa, procedeu-se ao cotejo entre as classificações adotadas e o conjunto mais geral de informações descritivas pormenorizadas sobre os agentes, as quais envolvem: atividade(s)/cargo(s) ocupados pelo pai; descrição do universo familiar com destaque para a descendência materna e paterna, a(s) atividade(s)/ cargo(s) do(s) irmão(os), e as estratégias matrimoniais individual e familiar.

A variável destinada ao tratamento estatístico, composta por esse conjunto de informações que compreendem as origens sociais, privilegiou, sempre que possível, o cargo mais alto descrito nas atividades do pai. No entanto, isso coloca uma série de dificuldades, dentre as quais o problema associado à definição da hierarquia dos postos ou títulos relativamente ao contexto histórico em pauta. Além disso, em muitos dos casos há uma multiplicidade de atividades e cargos que descrevem a condição social de origem; em outros, há apenas a alusão a indicadores gerais tais como "doutor" ou "coronel”, ou a reconhecimento da família como "abastada", "tradicional" ou de "prestígio", por exemplo. Contudo, muito antes de tratar isso como um problema, buscou-se tomar a multiplicidade de predicados que compõem os perfis dos agentes como algo a ser analisado, principalmente em suas relações com as estratégias de re- produção social. Trata-se, então, de levar a sério a extensão das redes de relações familiares, o conjunto de recursos passíveis de serem acionados e as possibilidades de conversão dos capitais herdados em posições específicas. No que se refere aos destinos, considerando os interesses deste artigo, foi utilizada apenas a primeira ocupação descrita nas carreiras. No caso desta informação, o principal limite está na dificuldade em identificar a sequência de postos ocupados pelos agentes, o que limita a interposição das relações entre as origens sociais, formação escolar e a primeira atividade que compõem as carreiras. 0 objetivo geral do presente artigo é, portanto, identificar o peso da escolarização para as estratégias de reprodução social das frações de classe em pauta, e expor as homologias entre as condições sociais de origem, a escolarização e as primeiras ocupações que compõem as carreiras dos agentes em pauta.

\section{As estratégias de reprodução: origens e destinos sociais}

É relativamente às transformações em curso na segunda metade do XIX e ao estado dos instrumentos de reprodução disponíveis, que se definem as estratégias visando manter ou ampliar o patrimônio e, por meio deste, a posição na hierarquia social. Dependentes do capital a ser reproduzido e das condições sociais de sua reprodução, os investimentos dos quais indivíduos e grupos lançam mão conectam-se aos esquemas classificatórios e aos princípios de hierarquização social vigentes. Portanto, é a partir das relações entre origens e chances desiguais de aquisição ou reprodução dos patrimônios herdados, que se apreende a "causalidade do provável"- sistema de expectativas de futuro que são dependen- 
tes da própria história social de acesso aos recursos e posições disponíveis em determinado estado das relações de força entre classes e frações de classe. Conectadas às percepções práticas sobre os processos de classificação e desclassificação que atingem as posições em vista, as expectativas se ancoram nas possibilidades diferenciais de apropriação e apreciação dos meios de acesso necessários aos fins pretendidos. Traduzidas em um sistema de ações e reações, as estratégias de reprodução se expressam nos modos através dos quais um grupo busca manter ou modificar sua posição na estrutura social, ela mesma em mudança. Isso faz com que o próprio grupo não possa realizar o seu objetivo senão através de uma ação que visa "transformar para se manter” (BOURDIEU, BOLTANSKI e SAINT MARTIN, 1973, p. 112).

0 primeiro indicador mais geral e situacional que permite localizar os agentes em pauta, aponta para o contraste entre a estrutura social em geral e as frações em pauta. Em termos mais específicos, enquanto aproximadamente $0,1 \%$ da população possui ensino superior no final do XIX, essa proporção salta para $88,9 \%$ ao focalizar os agentes em análise. Além disso, os analfabetos estão ausentes, enquanto compreendem 82,6\% da população brasileira no período ${ }^{1}$. Como destaca Ferraro (2002, p. 32), o analfabetismo representa um modo concreto de "rotulação, discriminação e estigmatização, constituindo a forma extrema de exclusão educacional". Neste contexto, o indicador de alfabetização, embora limitado, permite apreender indiretamente o estado geral do acesso à escolarização.
Além disso, os sentidos atribuídos aos que não sabem ler e escrever indicam a distância simbólica que os separa dos agentes em análise, e aponta para a linha que os separa dos demais. No Novíssimo Dicionário Latino-Português de Francisco Rodrigues dos Santos Saraiva, cuja primeira edição é de 1881, ao significado etimológico da palavra - aquele que não conhece o alfabeto -, estão ligados os significantes de ignorante, iletrado, agramático, idiota. Juntamente com a continuidade estrutural do analfabetismo (71,2\% em 1920), persistem também o conjunto de estigmas associados aos que não sabem ler. Na nona edição do Novo Dicionário da Língua Portuguesa ${ }^{2}$ de Antônio Candido de Figueiredo, publicado em 1913, o analfabeto é aquele "que é muito ignorante", que é "estúpido".

A exclusão do analfabeto do direito ao voto retoma, igualmente, o sistema de significantes que caracterizam aqueles que portam tal predicado. Isso fica evidente na noção de autonomia, princípio considerado fundamental para o acesso ao direito de expressar sua opinião livremente através do voto. Os que não sabem ler e escrever, portanto, são considerados não livres, incapazes de julgar e formar opinião, logo, dependentes daqueles capazes de discernir o mundo. Estão impressas nesta visão hierárquica do social as capacidades necessárias ao reconhecimento enquanto participante da sociedade política em constituição. Nestes termos, é garantido a uns o direito e o dever de conduzir os outros (FREITAS JUNIOR, 1881). No polo oposto aos estigmas associados aos que não leem nem escrevem, estão os que

1. Ferraro (2002) estima que no final do XIX, a proporção de analfabetos entre aqueles com mais de 15 anos - idade mínima para ingresso no ensino superior - seja de 77\%.

2. A primeira edição é de 1889 . 
são "versados em letras", aos quais uma série de significantes se conectam: "erudito", "jurisconsulto", “advogado”, “jurista”. Todos associados ao significado de "letrado" e "escritor". Em síntese, os "versados em letras" são aqueles que expressam suas posições políticas, literárias e científıcas através da escrita, constituindo o grupo de "intelectuais" ou especialistas em "cultura” capazes de produzir a leitura do real e, portanto, de agir sobre ele (PÉCAUT, 1990; CORADINI, 2003).

Em termos gerais, é possível completar as indicações acerca da relação com a oferta de escolarização no período, com as informações relativas às frações sociais de origem dos agentes em pauta, o que permite refınar os mecanismos de seleção social que estão na base de constituição das elites políticas e intelectuais do período. A partir da relativa estabilidade da estrutura social brasileira entre 1872 e $1920^{3}$, é possível estimar onde se situam os agentes em análise. Considerando as origens sociais e as possibilidades específicas de sua comparação com os dados do recenseamento de 1872, 37,4\% são filhos de proprietários, comerciantes, negociantes e/ou banqueiros, e outros $6,8 \%$ de profissionais liberais - frações que representam, em conjunto, 0,5\% da população no período. Mesmo a fração mais baixa no que tange às origens sociais dos agentes em análise, representada pelos funcionários públicos, pequenos comerciantes, trabalhadores especializados e militares (não oficiais) (8,8\%), corresponde a uma fração bastante reduzida da população no período $\left(1,5 \%{ }^{4}\right)$. Isso sig- nifica, grosso modo, que os agentes em pauta circulam no interior de frações que representam aproximadamente $2 \%$ da população brasileira do período.

De modo geral, dois princípios intervêm na configuração do espaço das estratégias de reprodução das elites em análise. 0 primeiro se define pela conexão entre as condições sociais de existência e a desigual distribuição dos instrumentos de reprodução, notadamente as instituições de ensino superior. 0 segundo, expressa o modo através do qual se relacionam as origens sociais com os investimentos escolares, permitindo, portanto, apreender as homologias entre o espaço das posições e o espaço dos destinos possíveis em termos de primeira ocupação. Há, pois, uma dinâmica que se expressa pelas condições regionais de possibilidade em seus confrontos com as transformações nos princípios de legitimação social e profissional, que marcam o Brasil da segunda metade do XIX, as quais se manifestam nas tendências mais gerais de aumento dos investimentos escolares para as gerações que nasceram após 1850 . Isso se define tanto pela ampliação da demanda por ensino superior $(80,1 \%$ para $86,6 \%)$ - contrapartida da redução dos que dispõem somente de ensino primário $(1,9 \%$ para $0,4 \%)$ ou secundário $(6,8 \%$ para $4,6 \%)$-, quanto pela importância relativa que assumem os cursos de ciências físicas e matemáticas, ou engenharia $(10,6 \%$ para $14,9 \%)$, e os de medicina ou farmácia (21,7\% para $32,5 \%)$, ante a queda pela demanda de diplomas de direito $(58,2 \%$ para $47,5 \%)$.

3. Para maiores detalhes, ver Bordignon (2015), especialmente capitulo 3.

4. Trabalhadores do comércio, inclusos. Tomando apenas os funcionários públicos, a fração da população em geral cairia para $0,1 \%$. 
Considerando os elevados custos para acesso e manutenção no ensino superior ${ }^{5}$, as estratégias são fortemente mediadas pela estrutura de oferta de diplomas, e pelas condições sociais de origem. 0 primeiro indicador mais geral da relação entre os agentes em pauta e o estado das instituições de ensino superior é o ano de conclusão dos cursos ${ }^{6}$ :
95,7\% obtiveram seus títulos durante o regime monárquico, período em que a oferta era bastante restrita. Em vista disso, ocorre uma espécie de regionalização do acesso ao ensino superior, a qual implica nas desiguais relações entre origens sociais e geográficas, escolarização e fileiras de ingresso na vida “profissional” (Gráfico 1).

\section{Gráfico 1: Plano fatorial: projeção das modalidades ativas e ilustrativas (Eixos 1 e 2).}

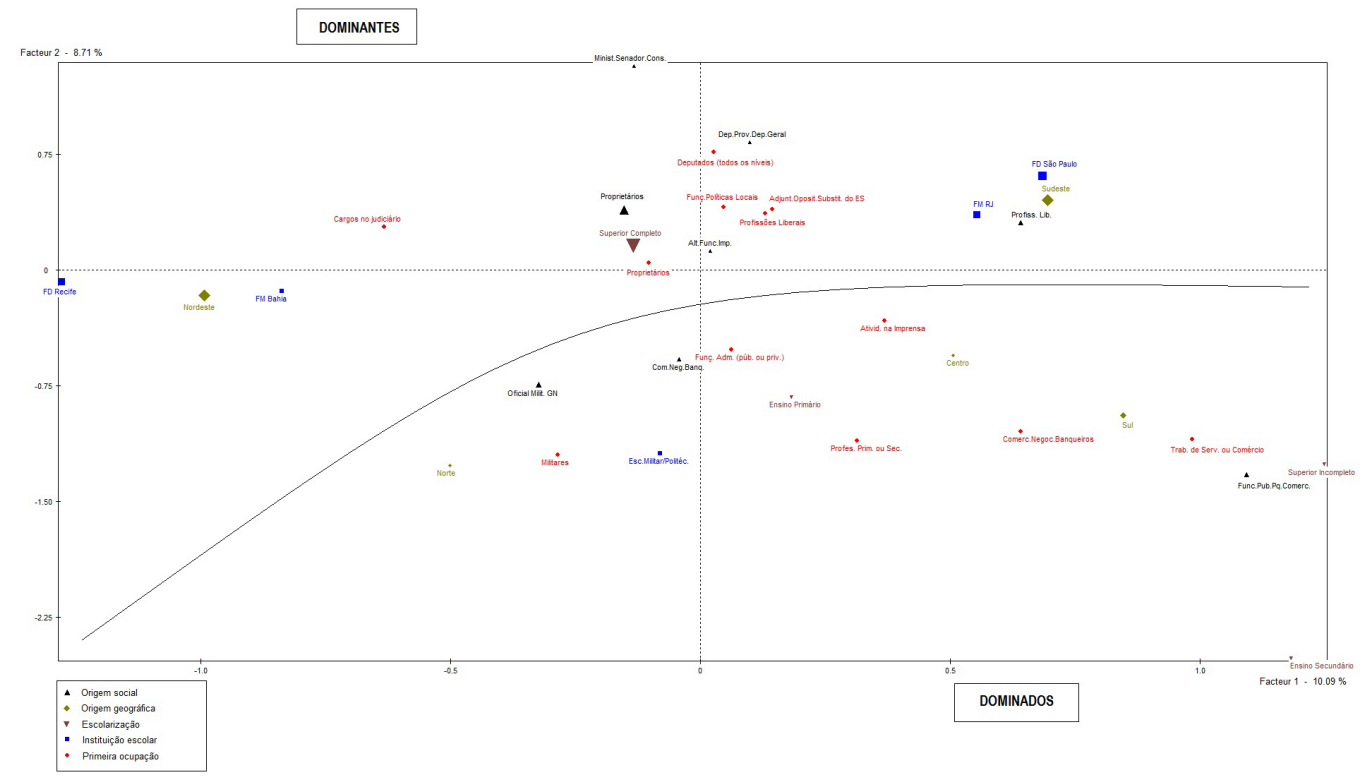

Fonte: elaborado pelo autor.

5. José Carlos da Cruz Jobim estima que, em 1874, a obtenção do diploma de ensino superior exija uma despesa de 12:000\$000. Anais do Senado, 1874, T. 2, p. 197.

6. Informação disponível para $88,8 \%$ da população em análise.

7. Para maiores detalhes, ver anexo estatístico. 
Na primeira dimensão (eixo do primeiro fator) do espaço das estratégias de reprodução há, portanto, uma oposição entre as regiões Norte e Nordeste, e as regiões Sul e Sudeste. Em termos gerais, isso expressa uma dinâmica de deslocamento historicamente constituída em direção às instituições de ensino superior, configurando uma espécie de regionalização de produção de diplomados ${ }^{8}$. Isso se verifica através do confronto entre origem geográfıca e instituição de destino: 63\% dos que nasceram nas regiões Norte e Nordeste destinam-se à Faculdade de Direito de Recife (50,3\%), ou à Faculdade de Medicina da Bahia (12,7\%), ao passo que 79,6\% dos provenientes das regiões Sul e Sudeste destinam-se à Faculdade de Direito de São Paulo (47,7\%), ou à Faculdade de Medicina do Rio de Janeiro (31,9\%). A regionalização é quebrada apenas no caso do investimento na Escola Politécnica do Rio de Janeiro, cuja proporção é mais significativa para os originários das regiões Norte e Nordeste (15,6\%), relativamente aos que nasceram no Sul ou Sudeste (11\%). As dinâmicas que entrelaçam local de nascimento e estratégias educativas, se sobrepõem ao espaço dos possíveis em termos de primeiras ocupações. Neste caso, há uma relação mais específica entre os originários das regiões Norte e Nordeste e o exercício de cargos - no Judiciário ou o ingresso na carreira militar -, os quais se opõem aos nascidos nas regiões Sul e Sudeste, mais voltados ao ingresso na carreira política - como deputados ou ocupantes de funções políticas locais -, ao exercício de profissões liberais ou à atuação como trabalhadores nas áreas de serviços ou comércio.

Evidentemente, ao sistema de relações entre as condições sociais de existência e as primeiras ocupações, se justapõem a estrutura diferencial de patrimônio que se visa transformar ou perpetuar. É especialmente nesta direção que se constitui o segundo eixo fatorial, estruturado pelas homologias específicas que definem as relações entre origens, escolarização e destinos sociais. Em termos gerais, portanto, se a primeira dimensão que estrutura o espaço das estratégias de reprodução das elites políticas e intelectuais em fins do XIX se define, fundamentalmente, pelas oportunidades decorrentes do estado dos instrumentos de reprodução disponíveis, a segunda dimensão se organiza com base nas formas diferencias que constituem as relações entre os agentes, ou frações em pauta, e tais instrumentos. Consequentemente, no caso das oposições constituídas pela relação entre origem geográfica e estrutura do espaço escolar, intervêm os efeitos de transição do eixo econômico em direção ao sudeste, e os efeitos da decadência econômica que atinge frações consideráveis das elites açucareiras. Um indicativo disso é a tendência de que os originários das regiões Norte e Nordeste passem a buscar abrigo nos cargos do Judiciário ou no serviço militar, ao passo que há uma maior diversidade de destinos entre aqueles que vêm do sul e do sudeste do país. As chances de aquisição, os modos de apropriação e os usos dos títulos escolares, no entanto, variam relativamente às origens sociais e incidem, portanto, nos destinos possiveis.

A composição da segunda dimensão se constitui pela força das relações entre origem social e escolarização. Num polo, situam-se aqueles com diploma de ensino superior, particularmente de direito 
e medicina, notadamente formados pela Faculdade de Direito de São Paulo e pela Faculdade de Medicina do Rio de Janeiro. No primeiro caso, há uma relação mais direta com o ingresso via cargos no Judiciário, através da advocacia, ou como deputados gerais ou provinciais, com origens sociais situadas nas frações política e economicamente dominantes do regime monárquico. No segundo, a tendência é que passem a atuar no interior da própria instituição de formação, como adjuntos, opositores ou substitutos no ensino superior, ou através do exercício da clínica médica, o que vem a reproduzir, tendencialmente, as origens sociais situadas na categoria dos profissionais liberais. No extremo oposto desse eixo, encontram-se aqueles com passagem pelo ensino militar ou politécnico, ou com níveis de ensino mais baixos (superior incompleto, secundário ou primário). No caso dos primeiros, os destinos são propensos a reproduzir as origens sociais situadas na categoria dos oficiais militares ou da Guarda $\mathrm{Na}$ cional: realização prática de uma espécie de inércia social. No caso daqueles com ensino superior incompleto, o fracasso escolar, concretizado pelo abandono do ensino superior, retoma as lógicas inscritas nas próprias condições de possibilidade de obtenção desses títulos. Quer dizer, normalmente não concluem o ensino superior aqueles com origens sociais mais baixas e, portanto, mais distantes do universo escolar e das condições de ingresso e permanência nas faculdades existentes. As pessoas com ensino secundário ou primário tendem a iniciar suas atividades "profissionais" como comerciante, negociante ou banqueiro, indicando a baixa penetração dos títulos escolares para a reprodução destas ocupações, bem como os efeitos da estrutura de patrimônio que as famílias ou grupos tencionam manter.

As chances sociais desigualmente distribuídas estão, assim, na base das propensões ao provável, as quais são dependentes, por sua vez, das oportunidades objetivas de lucro e do conhecimento prático que permitem a apreciação dos investimentos. As estratégias educacionais acionadas pelos grupos familiares estão, consequentemente, na base de um conjunto de deslocamentos possíveis, notadamente em termos de colocação no "mercado de trabalho" e/ou reprodução das posições sociais. As chances desiguais de acesso à escolarização estão intimamente ligadas às suas condições sociais de realização. Sendo assim, as origens sociais se colocam no centro dos mecanismos de seleção e exclusão a partir dos quais se definem as condições de possibilidade de obtenção dos títulos escolares. Isso fica evidente na correlação entre origens sociais e escolarização (Tabela 2), visto que as chances de acesso aos níveis escolares mais elevados variam relativamente às posições sociais de origem. Para os estratos mais baixos, o limite mais provável é ensino secundário, ou mesmo, o ensino superior incompleto. Em contraposição, aqueles provenientes das frações sociais ligadas ao exercício de altos cargos na burocracia, à ocupação de cargos eletivos, às profissões liberais e à condição de proprietário encontram, com mais frequência, abrigo no ensino superior. 


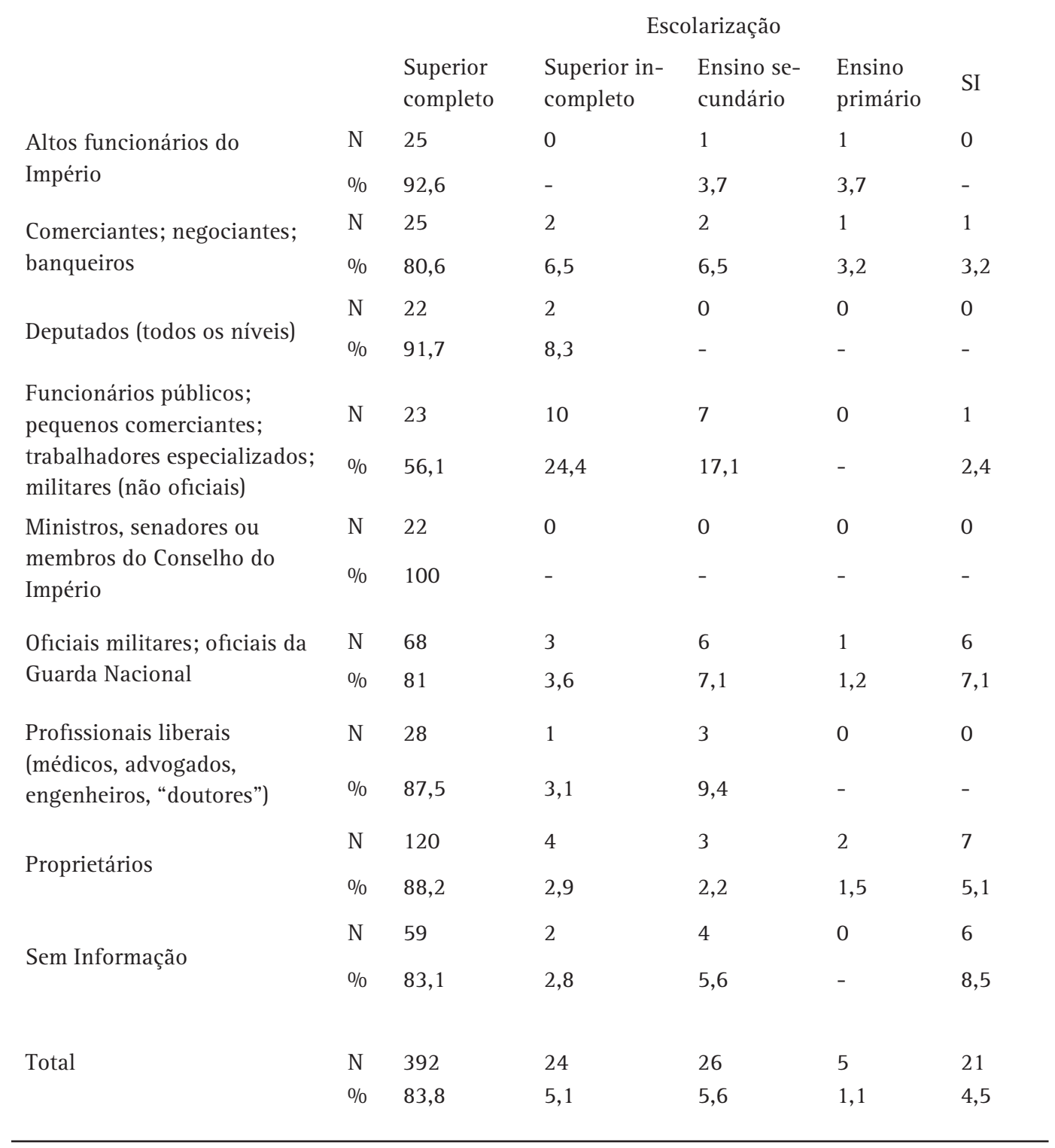

Fonte: elaborada pelo autor.

No polo dominante do eixo do segundo fator, as faculdades de direito representam um espaço para onde confluem os investimentos de distintos grupos sociais. Assim, filhos de deputados (66,7\% contra 49,4\% do conjunto do universo), ministros, senadores ou membros do Conselho de Estado do Império (72,7\% contra 49,4\% do con- junto do universo) e proprietários (55,9\% contra 49,4\% do conjunto do universo) se destinam majoritariamente à obtenção de diplomas de direito. No caso dos proprietários, isso indica uma tendência geral de reconversão dos seus descendentes às classificações ocupacionais mais legítimas no horizonte dos processos de modernização 
da segunda metade do XIX, quer dizer, trata-se de fornecer uma tintura cultural aos descendentes das frações que passavam a ser, cada vez mais, identificadas como entraves ao progresso do país. A homologia entre origens sociais, título escolar e a frequência a determinadas instituições conecta-se, de modo significativo, aos contextos regionais de formação e inserção. A passagem pelos cursos jurídicos favorece o ingresso nas atividades de imprensa (12,1\% contra 9,8\% do conjunto do universo), nos cargos de deputado geral ou provincial $(7,4 \%$ contra $5,1 \%$ do conjunto do universo), além de servirem como garantia de acesso aos cargos no Judiciário (34,2\% contra $17,1 \%$ do conjunto do universo).

No entanto, no espaço multidimensional constituído pelas estratégias de reprodução, os contextos regionais intervêm de modo significativo nas homologias entre o espaço das posições sociais e o das ocupações de destino. No caso da Faculdade de Direito de São Paulo, há uma associação significativa com as atividades na imprensa (13,4\% contra 9,8\% do conjunto do universo), a ocupação de cargos no Judiciário (26,8\% contra $17,1 \%$ do conjunto do universo), o acesso à carreira eletiva como deputado $(10,2 \%$ contra 5,1\% do conjunto do universo) e o exercício de profissões liberais (33,9\% contra 29,1\% do conjunto do universo). A estrutura do espaço dos possíveis "profissionais" liga-se, pois, aos investimentos familiares nessa instituição, destino preferencial dos filhos de altos funcionários do Império $(33,3 \%$ contra $27,1 \%$ do conjunto do universo), de deputados $(45,8 \%$ contra $27,1 \%$ do conjunto do universo), de ministros, senadores ou conselheiros do Império (50\% contra 27,1\% do conjunto do universo), e de proprietários (30,9\% contra 27\% do conjunto do universo). Os percursos, no entanto, se diferenciam relativamente às origens sociais, enquanto os filhos dos altos funcionários do Império com passagem pela Faculdade de Direito de São Paulo destinam-se aos cargos no Judiciário, os de ministros, senadores e conselheiros têm maior propensão aos postos eletivos de deputado provincial ou geral, ou ao exercício da advocacia. A atuação como advogado é, também, o destino tendencialmente mais forte entre filhos de deputados provinciais ou gerais, e de proprietários.

Enquanto a passagem pela Faculdade de Direito de São Paulo configura uma maior diversifıcação nas relações entre origens e destinos, a passagem pela Faculdade de Direito de Recife (PE) possibilita um leque de possibilidades "profıssionais" menos diverso, e caracterizando uma posição dominada entre os dominantes. A passagem por este curso jurídico prepara, majoritariamente, para o exercício de cargos no Judiciário como primeira ocupação (45\% contra 17,1\% do conjunto do universo). Isso se especifica pela relação que os filhos de proprietários (25\% contra 21,4\% do conjunto do universo), e de oficiais do Exército ou da Guarda Nacional estabelecem com a Faculdade de Direito de Recife, e o posterior deslocamento dos primeiros em direção aos cargos no Judiciário (45\% contra 17,1\% do conjunto do universo), e dos segundos para a atuação na imprensa (22,2\% contra 10\% do conjunto do universo). Em ambos os casos, tal movimento expressa a reconversão de filhos de proprietários em direção às sinecuras do Estado, e à fuga dos filhos de oficiais do Exército ou da Guarda Nacional de uma ocupação em progressiva desclassificação.

Igualmente situado no polo dominante do eixo do segundo fator, os cursos de medicina e de farmácia estão no centro das estratégias escolares dos descendentes de 
profissionais liberais (50\% contra 26,3\% do conjunto do universo). No entanto, a agregação dos cursos que representam parte dos diplomas oferecidos pelas faculdades de medicina do período ${ }^{9}$, encobrem seus significados sociais e as barreiras que constrangem em direção à medicina ou à farmácia. Em termos gerais, os critérios de entrada nos diferentes cursos servem como um indicador indireto dos mecanismos de seleção social que os diferenciam: enquanto o acesso ao curso de medicina exige exames preparatórios de dez matérias, para o curso de farmácia é necessária a habilitação em três. Neste quadro, o peso fundamental está na exigência de línguas: latim, francês e inglês para a medicina; francês para a farmácia. Os critérios de acesso aos cursos se modificam com a reforma de $1884^{10}$, porém as diferenças permanecem, notadamente no que tange ao conhecimento de línguas: passa-se a exigir também o português e o alemão para o curso de medicina, e o português e o latim para o de farmácia. Os exames necessários ao ingresso nos cursos repercutem nas relações entre origens sociais e os tipos de diplomas visados. Assim, os cursos de medicina aparecem como parte das estratégias escolares dos descendentes de proprietários, e de comerciantes, negociantes e banqueiros, ao passo que os cursos de farmácia aparecem no quadro dos investimentos dos filhos de funcionários públicos, pequenos comerciantes, trabalhadores especializados ou militares (não ofıciais). No caso dos últimos, é fundamental notar que, quando se destinam ao curso de medicina, são os que não o concluem (7,3\% contra $1,1 \%$ do conjunto do universo).
Como para as faculdades de direito, as relações diferenciais com as faculdades de medicina se definem relativamente ao conjunto das divisões territoriais e sociais. Neste caso, a Faculdade de Medicina do Rio de Janeiro ocupa uma posição estruturalmente dominante, sobretudo por sua posição central na reconversão de filhos de proprietários em direção às profissões liberais $(74,1 \%$ contra 53,1\% do conjunto do universo), ou de filhos de oficiais militares ou da Guarda Nacional aos cargos iniciais na carreira docente - adjuntos, opositores, substitutos do ensino superior (25\% contra 15,4\% do conjunto do universo). No caso da passagem dos filhos de funcionários públicos, pequenos comerciantes, trabalhadores especializados ou militares (não ofıciais) pela Faculdade de Medicina do Rio de Janeiro, a tendência é que iniciem suas ocupações através de atividades como trabalhadores dos serviços ou comércio (25\% contra 3,3\% do conjunto do universo). No caso da Faculdade de Medicina da Bahia, equivalente estrutural da Faculdade de Direito de Recife (PE), a passagem por seus bancos tem pouco efeito para o destino dos filhos de proprietários, significativamente voltados ao exercício de funções políticas locais (28,6\% contra 6,7\% do conjunto do universo). Ao contrário, tem um peso mais visível para os filhos de oficiais militares ou da Guarda Nacional, com tendência à reconversão para o exercício da medicina $(57,1 \%$ contra $53,3 \%$ do conjunto do universo).

No polo dominado do eixo do segundo fator, encontra-se a Escola Politécnica do Rio de Janeiro, a qual ocupa o centro das

9. A partir da reforma de 1854, os cursos de obstetrícia e de farmácia passam a compor os tipos de diplomas dispensados pelas faculdades de medicina. Em 1884, ocorre a inclusão do curso de odontologia. 10. Decreto n. 9.311 , de 25 de outubro de 1884 . 
estratégias escolares dos filhos de oficiais militares ou da Guarda Nacional (21,4\% contra $12,4 \%$ do conjunto do universo), tendencialmente voltados ao ingresso nas carreiras militares. Igualmente, a formação em ciências físicas e matemáticas ou em engenharia representa uma espécie de reconversão por acumulação aos filhos de proprietários, os quais, após a passagem pela Escola Politécnica, ingressam na carreira militar ${ }^{11}$. Além desta relação específica entre origens, escolarização e destino que marca os descendentes das frações de oficiais militares ou da Guarda Nacional, há uma tendência significativa à reconversão às profissões liberais - 40,5\% investem nos cursos jurídicos, e $22,6 \%$ nos cursos médicos. De fato, ocorre uma desclassificação da carreira militar, produto da sobreposição de processos que visavam, por um lado, salvaguardar as "boas entradas" no oficialato e, por outro, garantir as dispensas do alistamento compulsório $^{12}$ aos que dispunham das características e/ou do capital social para tanto. Isso produz um movimento específico, primeiramente através do alistamento maciço de "homens brancos solteiros e pardos livres", e posteriormente, por conta da Guerra do $\mathrm{Pa}$ raguai, quando do alistamento de escravos ou de contingentes significativos de pobres livres transforma o perfil social da corporação (GRAHAM, 1997; KRAAY, 1999; T0RAL, 1995; SEIDL, 1999).

No polo dominado entre os dominados, estão aqueles sem ensino superior completo, ou que possuem níveis escolares mais baixos, tais como o ensino secundário ou o primário. Aqui ocorre uma espécie de acumulação de desvantagens, fazendo com que os destinos sejam mais diretamente dependentes das origens sociais. Neste sentido, os filhos de funcionários públicos, pequenos comerciantes, trabalhadores especializados ou militares (não oficiais) são os que estabelecem uma relação mais distante com o espaço dos diplomas dispensados pelas faculdades existentes, tendencialmente mais presentes entre aqueles que não concluem o ensino superior $(24,4 \%$ contra $5,1 \%$ do conjunto do universo), ou que possuem apenas o ensino secundário $(17,1 \%$ contra 5,6\% do conjunto do universo). Isso se reflete, efetivamente, na homologia com o espaço dos destinos possíveis. Entre os que dispõem de ensino superior incompleto, os filhos de funcionários públicos, pequenos comerciantes, trabalhadores especializados ou militares (não ofıciais) destinam-se mais significativamente às atividades de imprensa, enquanto os que têm ensino secundário tendem a trabalhar nos serviços ou no comércio. No caso dos filhos de proprietários ou de comerciantes, negociantes ou banqueiros sem ensino superior, a tendência é a reprodução das condições sociais de origem, ou o ingresso em funções políticas locais como primeira ocupação.

\section{Perfis, origens sociais e espaço dos pos- síveis}

De modo bastante significativo, as categorias de classificação tomadas para fins estatísticos encobrem uma multiplicidade de lógicas sociais de investimento e setores de atuação que se ligam às trajetórias do conjunto dos grupos familiares, ou mesmo, não raro, aos investimentos múltiplos que

11. Isso ocorre para 9 entre os 10 que dispõem deste perfil, dos quais 8 são das regiões Norte e Nordeste.

12. Instrução $n^{\circ} 67$, de 10 de julho de 1822 . 
caracterizam as carreiras e a posição social do pai. Isso significa que a apreensão completa do sistema de reprodução social depende da atenção específıca à multiplicidade das atividades que compõem as condições de origem, atentando para seus efeitos às estratégias de ampliação ou de manutenção das posições, e à divisão do trabalho de dominação. Portanto, o conjunto dessas clivagens torna-se mais específico ao se tomar o confronto entre as "categorias estatísticas" construídas e a descrição das atividades do pai e, na medida do possível, do conjunto do grupo familiar.

As atividades na imprensa representam, no período, o espaço privilegiado de realização da concepção de militância política como expressão da atividade intelectual (ADORNO, 1988). Normalmente, passam pela atuação na imprensa os filhos de altos funcionários do Império (22,2\% contra $9,8 \%$ do conjunto do universo), de deputados $(20,8 \%$ contra $9,8 \%$ do conjunto do universo) e de profissionais liberais (15,6\% contra 9,9\% do conjunto do universo). Como se trata de um universo de entrada mais permeável, não necessariamente ligado à posse de diplomas, torna-se atrativo, também, àqueles que têm suas origens entre frações sociais mais baixas, notadamente entre os funcionários públicos, pequenos comerciantes, trabalhadores especializados e militares $(17,1 \%$ contra $9,8 \%$ do conjunto do universo).

Um caso ilustrativo é Herculano Marcos Inglês de Souza, nascido no Pará, em 1853, e filho de Marcos Antônio Rodrigues de Souza, desembargador. Inglês de Souza formou-se na Faculdade de Direito de São Paulo, em 1876, ingressando na atividade jornalística através da fundação da Revista Nacional, em 1877, e da atuação junto ao Diário de Santos, em 1878. Mais do que alto funcionário do Império, seus pais eram de "famílias tradicionais" (DICIONÁRIO DA ELITE POLÍTICA REPUBLICANA, n.d.). do Pará, situados na região de Óbidos, onde a família paterna ocupava historicamente os cargos no Judiciário. Além de juiz na região, o pai de Inglês de Souza foi deputado e presidente da Assembleia Provincial do Pará, transferindo-se, posteriormente, para Santos (SP), onde assumiu como juiz municipal. A passagem pela imprensa marca, também, os investimentos iniciais de José de Melo Carvalho Muniz Freire, nascido no Espírito Santo, em 1861. Filho de Manuel Feliciano Muniz Freire, engenheiro e deputado provincial, seu pai era proprietário do Jornal de Vitória, órgão do Partido Liberal estadual. Pelo lado materno, descendia de uma "poderosa família de Vitória" (DICIONÁRIO DA ELITE POLÍTICA REPUBLICANA, n.d.). Ingressou na Faculdade de Direito de Recife, e concluiu os estudos em São Paulo, onde atuou como redator-chefe d'O Liberal Acadêmico, jornal ligado ao Partido Liberal. Nessa ocasião, casou-se com Colatina Soares de Azevedo, neta de Joaquim Celestino de Abreu Soares, Barão de Paranapanema, um dos maiores proprietários rurais e produtores de café da região de Campinas (SP).

A obtenção de diploma de bacharel em direito funciona, igualmente, como princípio de legitimação para acessar os cargos no Judiciário que, pela própria estrutura de oportunidades, se apresentam numa espécie de reserva de mercado aos titulares desses diplomas, garantindo ganhos regulares e o controle formal sobre instâncias burocráticas e de mediação entre o poder central e o local. No entanto, dependendo das condições sociais de origem, o acesso aos cargos judiciários pode assumir uma conotação específica: 1) funciona como 
uma extensão do poder local ligado ao clã familiar; 2) constitui-se como uma salvaguarda de recursos econômicos e status social. Em termos gerais, há uma associação significativa entre os filhos de altos funcionários do Império (33,3\% contra 17,1\% do conjunto do universo), e de proprietários (20,6\% contra $17,1 \%$ do conjunto do universo), e a ocupação desse tipo de cargo no início da carreira. No primeiro caso, o perfil de Manuel Antônio Murtinho, nascido em Mato Grosso, em 1845, é exemplar. Filho de José Antônio Murtinho, médico e presidente da província do Mato Grosso durante o Império, o investimento familiar na escolarização dos filhos homens é significativo, todos os sete obtiveram diplomas, incluindo Manuel Murtinho, bacharel em direito pela Faculdade de Direito de São Paulo, em 1869. Após formado, volta para o Mato Grosso, onde assume como juiz municipal e de órfãos em Poconé e, posteriormente, em São Luís de Cáceres. É o mesmo caso de José Cândido de Albuquerque Mello e Mattos, nascido na Bahia, em 1864. Filho do desembargador da Relação de Cuiabá, Carlos Esperidião de Mello Mattos, inicia seus estudos na Faculdade de Direito de São Paulo, transferindo-se para Recife (PE), onde se forma em 1887. Após a obtenção do título, foi nomeado promotor em Queluz (MG), onde permaneceu até 1889 , conseguindo o deslocamento para a cidade do Rio de Janeiro.

Dos filhos de proprietários que passam pelos cargos judiciários no início da carreira, um caso exemplar é o de Antônio Torquato Fortes Junqueira, nascido em Minas Gerais, em 1839, filho de José
Frausino Junqueira, sargento-mor e proprietário, descendente de Gabriel Francisco Junqueira - Barão de Alfenas. A família estava instalada na região de Baependi (MG), onde possuía inúmeras fazendas dedicadas ao cultivo de café e à criação de cavalos de raça, além de alguns escravos ${ }^{13}$. Antônio Torquato fez seus estudos na Faculdade de Direito de São Paulo, obtendo o título em 1863, quando retorna a Minas Gerais e assume a promotoria e, posteriormente a judicatura, em Baependi, onde sua família dispunha de forte poder econômico e político. Nesse polo, encontra-se também a trajetória de Urbano dos Santos Costa Araújo, que nasceu no Maranhão, em 1859, e era filho do proprietário e coronel da Guarda Nacional, Antônio Brício de Araújo, cuja família possuía forte poder político na região de Guimarães (MA). Tanto Urbano dos Santos quanto seu irmão, homônimo do pai, formaram-se pela Faculdade de Direito do Recife (PE) e ocuparam cargos no Judiciário, notadamente a promotoria e judicatura no Maranhão.

Se os filhos de proprietários têm chances significativas de estreia na "vida profissional" através da obtenção de diplomas de direito e ingresso nos cargos judiciários, isso é igualmente válido para o début através da ocupação de cargos representativos, notadamente deputados (7,4\% contra 5,1\% do conjunto do universo), ou do exercício de profissões liberais (33,1\% contra 29,1\% do conjunto do universo). No primeiro caso, o perfil de José Luiz de Almeida Nogueira é ilustrativo: filho de Pedro Ramos Nogueira - Barão de Joatinga, proprietário de terras, dentre as quais, uma ilha em Angra dos

13. 0 inventário do Coronel Antônio Luis de Noronha e Silva encontra-se disponível em: <http://www. projetocompartilhar.org/DocsMgAF/antonioluizdenoronhaesilva1855anadolinahonoriajunq1857.htm >. 
Reis e a Fazenda Loanda, em Bananal (SP), edificada por seu pai -, o Major José Ramos Nogueira, sargento-mor da Imperial Guarda de Honra de D. Pedro I, Almeida Nogueira estudou no Lyceu Bonaparte, em Paris, e formou-se pela Faculdade de Direito de São Paulo, obtendo o grau de doutor em 1874. Casou-se com Maria Amélia Domingues de Castro, filha de Manuel Jacinto Domingues de Castro - Barão de Paraitinga, chefe do Partido Conservador em São Paulo. No mesmo ano de sua formatura, “já possuía uma cadeira" na Assembleia Legislativa provincial, da qual seu sogro era presidente, alçando, posteriormente, o cargo de Deputado Geral (1876-77). No caso daqueles que reconvertem os investimentos para a advocacia, Antônio Januário Pinto Ferraz representa um caso exemplar. Nascido em São Paulo, em 1851, filho do proprietário e comendador Antônio Pinto Ferraz, ingressa na Faculdade de Direito de São Paulo em 1870, concluindo em 1874. Após formado, passou a advogar ao lado de Martim Francisco Ribeiro de Andrada III e, posteriormente, associou-se a Antônio Carlos Ribeiro de Andrada Machado e Silva II, primo de Martim Francisco, ambos da linhagem dos Andrada; também se associou a Luís Gama, formando, juntos, o "escritório mais afamado de seu tempo" (FACULDADE DE DIREITO DE SÃO PAULO, n. d.).

Em contraposição aos agentes com passagem pelas faculdades de direito, encontram-se aqueles cujo pai é oficial militar ou da Guarda Nacional, com fortes chances de reprodução das posições iniciais. Próximos a esse polo, estão os filhos de comerciantes, negociantes e banqueiros, particularmente por sua associação significativa com as instituições escolares militares ou a Escola Politécnica (16,1\% contra 12,4\% do conjunto do universo). A atração espe- cífica da carreira das armas aos filhos de oficiais decorre, principalmente, das "boas entradas” garantidas pela condição social de origem, o que garante um certo fluxo mesmo em um contexto de desvalorização. Conecta-se a esse fenômeno histórico, o fato de que uma parcela significativa das famílias de oficiais militares ou da Guarda Nacional tende a redirecionar seus investimentos para outras espécies de diplomas, notadamente direito e medicina. Ilustrativo dessas relações é o caso de Júlio Anacleto Falcão da Frota, nascido em Santa Catarina, em 1836. Filho de Antônio José Falcão da Frota, oficial da marinha portuguesa que acompanhou D. João VI na ocasião da vinda da corte para o Brasil, Júlio Anacleto, assim como seu irmão Antônio Nicolau, assentou praça e ingressou na Escola Militar do Rio de Janeiro. Obtendo o reconhecimento de cadete, concluiu o curso e atuou na Comissão de Engenheiros Militares do Mato Grosso, durante a Guerra do Paraguai. Caso semelhante é o de Francisco de Paula Alencastro, nascido no Rio Grande do Sul, em 1853. Filho do general José Joaquim de Alencastro, assentou praça em 1868, fez o curso de cavalaria e passou para alferes, em 1875. No caso do investimento em outros tipos de diplomas, notadamente no de direito, é ilustrativo o perfil de José Leopoldo de Bulhões Jardim, descendente de uma família há várias gerações ligada à carreira das armas. Nascido em 1856, em Goiás, onde sua família detinha o controle da política regional, era filho do major Inácio Soares Bulhões e neto do coronel José de Rodrigues Jardim, presidente da província, senador do Império e chefe do Partido Liberal local. Leopoldo Bulhões formou-se na Faculdade de Direito de São Paulo, em 1880, retornando a Goiás, onde assume a redação do Tribuna Livre, órgão do Partido 
Liberal goiano, elegendo-se, em seguida, deputado geral. Igualmente ilustrativo, é o caso de Domingos Olímpio Braga Cavalcanti, nascido no Ceará, em 1851: era filho de Antônio Raymundo de Hollanda Cavalcanti, major da Guarda Nacional, comerciante, vereador, juiz municipal e titular de inúmeros cargos de nomeação do Império. 0 conjunto das estratégias familiares configura uma divisão do trabalho de dominação: Domingos Olímpio destinou-se ao curso de direito, formando-se na Faculdade de Direito de Recife, retornando ao Ceará onde exerce a promotoria pública, dois de seus irmãos seguiram a carreira das armas, passando pela Escola Militar, e outro dedicou-se à administração dos negócios comerciais da família.

A relação historicamente constituída entre as frações militares e os serviços médicos, abre uma das portas aos descendentes de oficiais, notadamente pelo investimento nas carreiras de professor de ensino superior nas faculdades de medicina (6\% contra 5,1\% do conjunto do universo), ou, em menor grau, pelo exercício da clínica. Nesse caso, é ilustrativo o caso de João Pizarro Gabizo, nascido no Rio de Janeiro, em 1845, descendente de uma família de militares portugueses instalados em Santos (SP). Filho de Antônio José Fernandes Pizarro Gabizo, tenente-coronel e capitão de caçadores em São Paulo, instalando-se, posteriormente, no Rio de Janeiro, onde chegou a coronel e integrou a comissão administrativa do Hospital Militar da Guarnição da Corte (RJ), João Pizarro Gabizo formou-se em medicina pela Faculdade de Medicina do Rio de Janeiro, atuando como cirurgião do Exército durante a Guerra do Paraguai e, posteriormente, ingressando na carreira docente na Faculdade de Medicina do Rio de Janeiro. Era primo de João
Joaquim Pizarro, também descendente de militares e professor na mesma instituição. É também ilustrativo o perfil de Joaquim Manuel Rodrigues Lima, nascido na Bahia em 1845, filho do capitão e proprietário Joaquim Rodrigues Lima: fez seus estudos na Faculdade de Medicina da Bahia, formando-se em 1862, retornando à região de Caetité (BA), onde se dedica ao exercício da medicina. Nesse período, casa-se com Maria Vitória Gomes de Albuquerque Lima, filha de José Antônio Gomes Neto - Barão de Caetité, juiz, intendente municipal e rico proprietário de terras na região (DICIONÁRIO DA ELITE POLÍTICA REPUBLICANA, n.d.). Outro caso ilustrativo é o de Tristão de Oliveira Torres, nascido no Rio Grande do Sul, em 1853, descendente de uma família de militares portugueses instalados na região de Viamão (RS). Seu avô paterno, alferes Bernardo da Costa Torres, era donatário de sesmaria, assumida por seu pai, coronel Sezefredo da Costa Torres, comandante superior da Guarda Nacional na comarca do Rio dos Sinos (RELATÓRIO, 1882, p. 9). Do lado materno, seu avô, capitão Manuel Inácio de Souza Oliveira Salazar, era filho do sargento-mor Custódio de Souza Oliveira Salazar, instalado na região de Osório (RS). Após formar-se em medicina pela $\mathrm{Fa}-$ culdade de Medicina do Rio de Janeiro, em 1878, retornou ao Rio Grande do Sul, onde exerceu a clínica médica, ingressando, posteriormente, no quadro de professores da Faculdade de Medicina e Farmácia de Porto Alegre (RS).

A desvalorização das carreiras médicas no início do XIX, no Brasil, principalmente por sua associação aos "cirurgiões", implica em um conflito de valorização "profıssional" que tem seu marco na transformação das Academias Médico-Cirúrgicas em Faculdades de Medicina, a partir de 1832. 
Desse modo, os cursos médicos se apresentam como "mais abertos" aos agentes provenientes de categorias que indicam posições sociais mais baixas, tal como a de funcionários públicos, pequenos comerciantes, trabalhadores especializados e militares (26,8\%). De maneira geral, a redução das bases sociais significativamente associadas aos cursos médicos, indica um processo específico de fechamento social, notadamente pela forte correlação entre esses diplomas e as modalidades de ingresso na vida "profissional”. De modo mais específico, as relações significativas se resumem às atividades docentes nos cursos médicos (14,5\% contra 5,1\% do conjunto do universo), ou ao exercício da clínica (50,8\% contra 13,5\% do conjunto do universo) e da farmácia (2,4\% contra $0,6 \%$ do conjunto do universo). Isso favorece, sensivelmente, a relação estabelecida entre filhos de profissionais liberais e o investimento em diplomas médicos (50\% contra 26,5\% do conjunto do universo), ou seja, há uma tendência acentuada à formação de famílias especializadas na oferta de serviços médicos.

Alguns casos são ilustrativos dessas tendências. Um deles é o caso de Domingos José Freire Junior, nascido no Rio de Janeiro, em 1842. Filho de Domingos José Freire, "educador" e diretor do Colégio São Cristóvão (RJ), ingressou na Faculdade de Medicina do Rio de Janeiro, obtendo o título em 1866, iniciando a carreira na mesma instituição como opositor de ciências assessórias, em 1871. Outro é o de Vicente Clímaco Damásio, nascido na Bahia, em 1838, filho de Francisco Borja Damásio, chefe de seção na Tesouraria da Fazenda da Bahia (CONSELHO DE ESTADO, 1871, p. 543) que, após formar-se na Faculdade de Medicina da Bahia, em 1859, ingressou como professor do Liceu Provincial da Bahia e da
Faculdade de Medicina, em 1862. No caso de Raulino Júlio Adolfo Horn, nascido em Santa Catarina, em 1849, filho do imigrante e boticário alemão Eduardo Amadeus Otto Horn, proprietário de uma botica, o investimento escolar passa pelo deslocamento geográfico e a obtenção do título de farmacêutico na Faculdade de Medicina do Rio de Janeiro, juntando-se ao pai no exercício da farmácia, em Santa Catarina. 0 caso de Belisário Augusto Soares de Souza é, também, representativo. Nascido no Rio de Janeiro, em 1862, filho do médico Francisco Manuel Soares de Souza, chefe do Partido Conservador na região de Cabo Frio (RJ), Belisário ingressa na Faculdade de Medicina do Rio de Janeiro, mas conclui o curso na Bahia, retornando ao Rio de Janeiro e instalando-se em Niterói, onde inicia no exercício da medicina.

Uma última oposição significativa se desenha pela clivagem entre os filhos de proprietários e os filhos de funcionários públicos, pequenos comerciantes, trabalhadores especializados e militares, com suas respectivas modalidades de investimento e chances sociais. No caso dos primeiros, há uma tendência significativa à manutenção das posições, e a estreia na vida "profissional” se dá através da gestão dos negócios da família (13,2\% contra 6,6\% do conjunto do universo). No que tange aos segundos, as condições de investimento são mais reduzidas, prevalecendo a atuação a imprensa, o ingresso no professorado primário e/ou secundário (22\% contra 4,9\% do conjunto do universo), ou os trabalhos no setor de serviços ou comércio $(12,2 \%$ contra $2,4 \%$ do conjunto do universo). Caso exemplar de filhos de proprietários que atuam, inicialmente, na gestão da herança familiar, é o de Gaspar Vasconcellos de Menezes Drummond Filho, nascido em Pernambuco, em 
1845, filho do homônimo, proprietário de muitos escravos e terras no estado, Gaspar Filho obtém o título de bacharel em direito, na Faculdade de Direito de Recife (PE), e retorna ao interior de Pernambuco, onde estão os negócios de família. Nessa mesma linha, situa-se o caso de Agostinho Vidal Leite de Castro, nascido em Minas Gerais, em 1841. Descendente de uma família extensa, era filho do "doutor" e proprietário Francisco de Sales de Oliveira e Castro, e neto paterno do Capitão Mateus Alberto de Souza Oliveira e Castro (HORTA, 1986). Sua mãe, Ana Teresa Vidal Leite Ribeiro, era filha de Francisco Leite Ribeiro, Capitão de Ordenanças, fundador de diversas fazendas e proprietário de escravos. Agostinho de Castro formou-se bacharel em direito pela Faculdade de Direito de São Paulo, em 1866, regressando a Minas Gerais, na região de Monte Verde, onde assume as propriedades da família e vem a exercer a advocacia (DICIONÁRIO DA ELITE POLÍTICA REPUBLICANA, n.d.).

Em oposição, situam-se aqueles cujas posições sociais de origem remetem às frações sociais mais baixas, significativamente mais associadas ao ensino superior incompleto e ao ensino secundário. É ilustrativo o caso de Alcindo Guanabara, nascido no Rio de Janeiro, em 1865. Filho de Manuel José da Silva Guanabara e Júlia de Almeida e Silva, ambos professores primários, concluiu os preparatórios e ingressou na Faculdade de Medicina do Rio de Janeiro, no entanto, abandonou o curso e passou a trabalhar como porteiro no Jockey Clube do Rio de Janeiro. Igualmente exemplar é o caso de Apeles José Gomes Porto Alegre, nascido no Rio Grande do Sul, em 1850, filho de Antônio José Gomes Porto Alegre, inspetor de alfândega de Rio Grande (RS). Após cursar o secundário no
Colégio Gomes, em Porto Alegre (RS), Apeles inicia as atividades como professor de ensino primário e secundário, porém não se trata apenas de um professor, mas de um fundador e proprietário de escola particular, o Colégio Rio-Grandense. No caso de Francisco de Paula Ney, nascido no Ceará, em 1858, a relação entre origens e destinos "profıssionais" se especificam na atuação em atividades de imprensa. Filho de Mariano de Melo Nei, alfaiate e "mestre de corte em Fortaleza”, Paula Ney estudou no Liceu Cearense e, posteriormente, ingressou na Faculdade de Medicina do Rio de Janeiro. No entanto, abandona o curso e dedica-se ao jornalismo.

A multidimensionalidade das classificações e, particularmente, seu efeito para a apreensão das estratégias de reprodução e dos mecanismos que fundamentam as divisões sociais e oportunidades, apontam para uma tendência significativa em direção às hierarquias constituídas a partir das condições sociais de possibilidade. Nesse caso, a passagem por instituições de ensino superior se constitui como um primeiro nível de acesso aos cargos e posições sociais mais elevados. 0 máximo proveito dos diplomas escolares associa-se, no entanto, ao conjunto de recursos herdados e suas possibilidades de reconversão em meios específicos aos cargos burocráticos disponíveis, ou à reivindicação de uma condição "profissional" tida como mais "moderna". Assim, não raro, descendentes de proprietários ou de frações sociais historicamente ligadas ao exercício da política e das carreiras das armas passam pelas instituições de ensino superior existentes, na busca de tinturas culturais e de reconversão em direção às novas simbologias de excelência em ascensão, reforçando a sociodiceia de seu próprio privilégio. 


\section{Considerações finais}

0 presente artigo se debruçou sobre o problema das estratégias de reprodução de determinadas frações de elite em fins do século XIX no Brasil. A partir disso, foi possivel identificar dois eixos centrais de articulação entre as variáveis analisadas 1) origens geográficas e sociais, 2) nível de escolarização e instituições escolares, e ponto de entrada nas carreiras. 0 primeiro deles está relacionado ao duplo processo histórico e social de configuração das relações entre frações sociais e instrumentos de reprodução. Assim, a restrição do espaço de oferta de diplomas, a transformação econômica, e a importação de novas ideias e ideais tidos e definidos como "modernos" no horizonte dos esquemas de percepção, apreciação e ação do período, ampliam a demanda por escolarização, ao mesmo tempo que redefine os diplomas mais legitimamente ligados às novas simbologias da excelência. Como resultado, desenha-se um segundo eixo ancorado na diferenciação das estratégias de reprodução relativas ao espaço dos possíveis sociais e institucionais em pauta. Em outros termos, entram em pauta as diferentes estruturas patrimoniais em confronto pela manutenção ou ampliação de suas posições, o que vem a desenhar um sistema de estratégias de reprodução equacionado pelas relações diferenciais que os agentes ou grupos estabelecem com as instituições de ensino e com os destinos possíveis.

Em termos gerais, três padrões compõem o quadro geral exposto, com suas diferentes especificidades. 0 primeiro deles se conecta aos agentes cujas origens sociais remetem às posições politicamente dominantes do período, em diferentes níveis, notadamente os filhos de altos funcionários do Império, de ministros, senadores ou conselheiros, e de deputados gerais ou provinciais. Trata-se de agentes que se destinam majoritariamente aos diplomas de ensino superior, e tendem a passar por cargos políticos eletivos em suas primeiras ocupações.

0 segundo padrão aponta para posições intermediárias, especialmente representadas pelos filhos de profissionais liberais, para os quais a obtenção de título escolar representa a continuidade dos empreendimentos familiares e, neste sentido, de manutenção dos serviços de advocacia ou de clínica médica, ou ainda de ocupação dos cargos públicos no Judiciário. Por fim, aparecem os descendentes das classificações que indicam o equivalente aos setores economicamente dominantes do período, quer dizer, os proprietários e os comerciantes, negociantes ou banqueiros, os quais, ao lado dos filhos de oficiais militares ou da Guarda Nacional, tendem ao investimento em diplomas de medicina ou de direito, numa espécie de fornecimento de tinturas cultuais aos seus descendentes. Em ambos os casos, o investimento escolar representa o centro das estratégias de reconversão e, portanto, uma luta contra a desclassificação, seja através do investimento em profissões liberais como primeira ocupação, ou pela ocupação de cargos no Judiciário. 0 aumento da demanda por escolarização atinge o conjunto das frações em análise, no entanto, as possibilidades de obtenção dos títulos escolares são desigualmente distribuídas. É assim que os descendentes de funcionários públicos, pequenos comerciantes, trabalhadores especializados ou militares (não ofıciais) esbarram mais comumente no ensino secundário, ou representam aqueles que, mesmo ingressando no ensino superior, não conseguem concluí-lo. Além disso, trata-se, igualmente, dos que tendem a reproduzir as condições sociais 
de origem em termos de primeira ocupação, indicando as diferentes possibilidades de usos dos títulos escolares.

Neste sentido, portanto, o artigo permitiu visualizar as homologias entre o espaço das condições sociais de existência, e o espaço das primeiras ocupações possíveis, colocando em evidência o espaço dos possíveis aberto às diferentes frações sociais, e o modo como as estratégias de reprodução se inscrevem nas posições de origem dos agentes em pauta.

\section{Referências}

ADORNO, S. Os aprendizes do poder: bacharelismo liberal na política brasileira. Rio de Janeiro: Paz e Terra, 1988.

ALONSO, A. Ideias em movimento: a geração de 1870 e a crise do Brasil Império. São Paulo: Paz e Terra, 2002.

BORDIGNON, R. R. Elites políticas e intelectuais no Brasil: condições de diversifıcação e estratégias de carreira (1870-1920). 2015. 410 f. Tese (Doutorado em Ciência Política) - Programa de Pós-Graduação em Ciência Política-PPGCP, Universidade Federal do Rio Grande do Sul, Porto Alegre, 2015.

As origens e o significado do regime republicano: interpretações em disputa. Anos 90, Porto Alegre, v. 23, n. 43, p. 235-266, 2016.

BOURDIEU, P. A distinção: crítica social do julgamento. Porto Alegre: Zouk, 2007.

BOURDIEU, P. ; BOLTANSKI, L. ; SAINT MARTIN, M. Les stratégies de reconversion: les classes sociales et le système d'enseignement. Social Science Information, 12 (5), p. 61-113, 1973.

CONINCK, F., GODARD, F. L'approche biographique à l'épreuve de l'interprétation. Les formes temporelles de la causalité. Revue française de sociologie., v. 31, n.1. p. 23-53, 1990.

CONSELHO DE ESTADO. Imperiais resoluções do Conselho de Estado, v. 5, 1871.
CORADINI, 0. L. Grandes famílias e elite "profissional' na medicina no Brasil. História, Ciências, Saúde - Manguinhos. III (3), Rio de Janeiro, 425466, 1997.

As missões da "cultura" e da "política": confrontos e reconversões de elites culturais e políticas no Rio Grande do Sul (1920-1960). Estudos Históricos, Rio de Janeiro, n. 32, p. 125-144, 2003. DICIONÁRIO DA ELITE POLÍTICA REPUBLICANA - CPDOC / FGV. Disponível em: <http://cpdoc. fgv.br/dicionario-primeira-republica >. Acesso em: Abril, 2019.

FACULDADE DE DIREITO DE SÃO PAULO, Galeria de Diretores. Universidade de São Paulo. São Paulo. Disponível em: <http://www.direito.usp.br/ faculdade/diretores/index_faculdade_ diretor_15. php>. Acesso em: Abril, 2019.

FERRARO, A. R. Analfabetismo e níveis de letramento no Brasil: o que dizem os censos? Educação e sociedade, Campinas, v. 23, n. 81, p. 21-47, 2002.

HORTA, C. R. As famílias governamentais de Minas Gerais. Análise \&t Conjuntura, Belo Horizonte, 1 (2), p. 111-142,1986.

GRAHAM, R.. Clientelismo e política no Brasil do século XIX. Rio de Janeiro: Editora da UFRJ, 1997.

KRAAY, H. Repensando o recrutamento militar no Brasil imperial. Diálogos, DHI/UEM, v. 3, n. 3, p. 113-151,1999.

"Em outra coisa não falavam os pardos, cabras e crioulos": o "recrutamento" de escravos na guerra de independência da Bahia. Revista brasileira de história, v. 22, n. 43, p. 109-126, 2002.

MICELI, S. La division du travail entre les sexes et division du travail de domination: un étude clinique des anatoliens au Brésil. Actes de la Recherche en Sciences Sociales, v. 1, n. 5-6, p. 162182, 1975.

. Intelectuais à brasileira. São Paulo: Companhia da Letras, 1999. 
PÉCAUT, D. Os intelectuais e a politica no Brasil: entre o povo e a nação. São Paulo: Ática, 1990.

RECENSEAMENTO DO BRASIL EM 1872. Departamento Geral de Estatística, 1876.

RECENSEAMENTO DO BRASIL EM 1890. Departamento Geral de Estatística. Rio de Janeiro: Oficina de estatística, 1898.

RELATÓRIO DO RECENSEAMENTO DO BRASIL DE 1900. Diretoria Geral de Estatística. Rio de Janeiro: Typographia da estatística, 1908.

RECENSEAMENTO GERAL DO BRASIL DE 1920. Diretoria Geral de Estatística. 5 volumes. Rio de Janeiro: Typographia da estatística, 1923-1930.
RELATÓRIO. Rio Grande do Sul (Província), vice-presidente (Antunes Maciel). 28 de outubro de 1882. Disponível em: http://memoria.bn.br/DocReader/Hotpage/HotpageBN.aspx?bib=252263\&pagfis=4949\&turl=http://memoria.bn.br/docreader\# . Acesso em: Abril, 2019.

SEIDL, E. A espada como "vocação": padrões de recrutamento e seleção das elites do Exército no Rio Grande do Sul (1850-1930). 1999. Dissertação (Mestrado em Ciência Política) - Programa de Pós-Graduação em Ciência Política-PPGCP, Universidade Federal do Rio Grande do Sul, Porto Alegre, 1999.

TORAL, A. A. A participação dos negros escravos na guerra do Paraguai. Estudos Avançados, v. 9, n. 24, p. 287-296, 1995.

\section{Apêndices}

Variáveis e modalidades

\begin{tabular}{|c|c|c|c|}
\hline \multicolumn{2}{|c|}{ Variáveis ativas } & Modalidades & $\begin{array}{l}\text { Modalidades após espe- } \\
\text { cificação de ilustrativas }\end{array}$ \\
\hline \multicolumn{2}{|c|}{ Origem geográfica } & 6 & 5 \\
\hline \multicolumn{2}{|c|}{ Origem social } & 9 & 8 \\
\hline \multicolumn{2}{|c|}{ Instituição de ensino superior } & 7 & 5 \\
\hline \multicolumn{2}{|c|}{ Escolarização } & 5 & 3 \\
\hline \multicolumn{4}{|c|}{ Eixos e valores associados } \\
\hline Eixo & Valor próprio & Porcenta & $\begin{array}{l}\text { Porcentagem } \\
\text { acumulada }\end{array}$ \\
\hline 1 & 0,4317 & 10,09 & 10,09 \\
\hline 2 & 0,3729 & 8,71 & 18,8 \\
\hline
\end{tabular}




\section{Contribuições (\%)}

$\begin{array}{lll} & \text { Eixo 1 } & \text { Eixo 2 } \\ \text { Origem geográfica } & 42,1 & 18,5 \\ \text { Origem social } & 10,2 & 33,5 \\ \text { Instituição de ensino superior } & 38,8 & 22,1 \\ \text { Escolarização } & 9,6 & 25,8 \\ \text { Total } & 100 & 100\end{array}$

Variável ilustrativa e valor-teste

Modalidades

Adjuntos, opositores, substitutos do ensino superior

Atividades na imprensa

Cargos no Judiciário

Comerciantes; negociantes; banqueiros

Deputados (todos os níveis)

Funções administrativas (públicas ou privadas)

Funções políticas locais

Militares

Professores do ensino primário ou secundário (público ou privado)

Profissões liberais

Proprietários

Trabalhadores de serviços ou do comércio
Valor-teste

Eixo 1

Eixo 2

0,72

1,99

2,66

$-2,37$

$-6,33$

2,77

2,44

$-3,99$

0,13

3,86

0,30

$-2,56$

0,15

1,30

$-2,06$

$-8,66$

1,55

$-5,47$

1,86

5,30

$-0,60$

0,25

3,31

$-3,70$ 
RESUMO

0 presente artigo se dedica ao exame das estratégias de reprodução das elites políticas e intelectuais no Brasil em fins do século XIX. Neste texto, são analisadas as relações entre origens geográficas e sociais, a escolarização e a primeira ocupação que compõem as carreiras dos agentes em pauta. 0 objetivo principal é apreender as estratégias de reprodução, e sua diferenciação relativamente aos recursos sociais e escolares que as respaldam, confrontando-as aos instrumentos disponíveis e às transformações na simbologia de excelência social. Os principais resultados apontam para a centralidade da desigualdade de chances no que tange às condições de escolarização e, igualmente, aos pontos de entrada das carreiras.

\section{PALAVRAS-CHAVE}

Origens sociais. Destinos. Estratégias de reprodução. Elites.

\section{SUMMARY}

This research dedicates itself to the examination of reproduction strategies from the political and intellectual elites in Brazil by the end of the 19th century. In this paper, we analyze the relations between geographical and social origins, schooling, and the first occupation that compose the agents' careers. The main goal is to apprehend the reproduction strategies and its differentiation with regards to the social and schooling resources that support the agents confronting them to the instruments that are available and the transformations in the social excellence symbology. The main results indicate the centrality of inequalities in terms of chances with regards to the conditions of schooling and, equally, to the career entrance points.

\section{KEYWORDS}

Social origins. Destination. Reproduction strategies. Elites. 
